\title{
Wielofunkcyjne smary krzemionkowe
}

\section{Multifunctional silica lubricating greases}

\author{
Agnieszka Skibińska \\ Instytut Nafty i Gazu - Państwowy Instytut Badawczy
}

\begin{abstract}
STRESZCZENIE: W artykule dotyczącym wielofunkcyjnych smarów przedstawiono zalety i wady smarów krzemionkowych, należących do grupy smarów wysokotemperaturowych zawierających nieorganiczny zagęszczacz. W części doświadczalnej przedstawiono właściwości fizykochemiczne próbek smarów krzemionkowych, zagęszczonych dwoma rodzajami krzemionki koloidalnej. Smary te zostały wytworzone w oparciu o pięć olejów bazowych o różnym charakterze chemicznym, należących do różnych grup według API: parafinowym, naftenowym, polialfaolefinowym, syntetycznym estrowym i roślinnym. Próbki smarów krzemionkowych charakteryzują się bardzo wysoką temperaturą kroplenia - nie kroplą do temperatury $300^{\circ} \mathrm{C}$, co pozwala na zastosowanie ich w wysokich temperaturach. Wytworzone próbki smarów na bazie olejów mineralnych i polialfaolefin wykazują się doskonałą stabilnością mechaniczną, na poziomie poniżej 2\% w badaniu według PN-C-04144, a smary na bazach biodegradowalnych - poniżej 10\%. Dla porównania, wysokotemperaturowe smary bentonitowe oraz smary na innym zagęszczaczu nieorganicznym charakteryzują się bardzo słabą stabilnością mechaniczną, przekraczającą nawet 100\%. Wszystkie uzyskane próbki smarów krzemionkowych charakteryzują się bardzo dobrą stabilnością strukturalną, potwierdzoną w badaniach skłonności smarów do wydzielania oleju. Zarówno w badaniu wydzielania oleju W wysokiej temperaturze, jak i pod obciążeniem, uzyskane wyniki nie przekraczają $1,5 \%(\mathrm{~m} / \mathrm{m})$. Smary krzemionkowe wykazują się bardzo dobrą odpornością na działanie wody w metodzie dynamicznej - podczas natrysku wody o temperaturze $79^{\circ} \mathrm{C}$ na obracające się łożysko uzyskane wyniki nie przekraczają $1,5 \%(\mathrm{~m} / \mathrm{m})$.
\end{abstract}

Słowa kluczowe: smar plastyczny, smar silikonowy, krzemionka koloidalna, oleje bazowe.

\begin{abstract}
The article presents multifunctional lubricating greases, as well as advantages and disadvantages of silica greases belonging to the group of high-temperature lubricating greases containing inorganic thickener. The experimental part presents the physicochemical properties of silica grease samples prepared with two types of fumed silica. These greases were made based on five base oils of various chemical nature, belonging to different groups according to API: paraffin, naphthenic, polyalphaolefin, synthetic ester and vegetable oil. Samples of silica greases have a very high dropping point, not dropping up to $300^{\circ} \mathrm{C}$, which allows their use at high temperatures. The samples of silica greases based on mineral oils and polyalphaolefins show excellent mechanical stability below 2\% according to PN-C-04144, and silica greases bases on biodegradable oils - below 10\%. For comparison, high-temperature bentonite greases and greases based on another inorganic thickener, have very poor mechanical stability, even exceeding 100\%. All obtained samples of silica greases are characterized by a very good structural stability, confirmed in tests of oil separation from greases under static conditions. Both in the oil separation test at high temperature and under load, the obtained results do not exceed $1.5 \%(\mathrm{~m} / \mathrm{m})$. Silica greases show very good water resistance in the dynamic method - when spraying water at $79^{\circ} \mathrm{C}$ onto a rotating bearing, the obtained results do not exceed $1.5 \%(\mathrm{~m} / \mathrm{m})$.
\end{abstract}

Key words: lubricating grease, silica grease, fumed silica, base oils.

\section{Wstęp}

Smar plastyczny to układ koloidalny, w którym zagęszczacz tworzy elastyczną przestrzenną sieć, utrzymując fazę ciekłą (fazę olejową). Właściwa struktura smaru jest utrzymywana dzięki istnieniu sił przyciągania powierzchniowego, sił kapilarnych oraz zjawisku adsorpcji powierzchniowej między zagęszczaczem i fazą ciekłą (Czarny, 2004; Total - poradnik).
Smary plastyczne są cieczami nieniutonowskimi, co oznacza, że ich lepkość zależy nie tylko od parametrów stanu $p, T$ (ciśnienia, temperatury), lecz także od gradientu prędkości, a także od czasu ich odkształcania. Wykazują one jednocześnie właściwości ciał stałych i cieczy. Pod działaniem niewielkich naprężeń ulegają odwracalnym odkształceniom, a gdy naprężenia przekroczą określoną wartość zaczynają płynąć jak ciecz (Krawiec, 2011). 
Olej (lub mieszanina olejów) jest podstawowym składnikiem smaru plastycznego. W większości smarów stanowi on 70-90\% $(\mathrm{m} / \mathrm{m})$. Wybór bazy olejowej decyduje m.in. o: właściwościach smarnych, zmianach właściwości w zależności od temperatury, odporności na utlenianie, właściwościach niskotemperaturowych, skłonności do odparowywania w podwyższonych temperaturach. Zagęszczacz, który stanowi około $7-25 \%(\mathrm{~m} / \mathrm{m}) \mathrm{w}$ istotny sposób wpływa na parametry eksploatacyjne smaru: teksturę, temperaturę kroplenia, odporność na działanie temperatury, stabilność mechaniczną, skłonność do wydzielania oleju ze smaru, odporność na działanie wody i właściwości reologiczne (Czarny, 2004).

W zależności od rodzaju zagęszczacza, smary dzielone są w następujący sposób:

- mydlane - z mydłami prostymi i kompleksowymi (smary wapniowe sodowe, litowe, glinowe, barowe);

- zawierające zagęszczacze mieszane (litowo-wapniowe, litowo-wapniowe kompleksowe, polimocznikowo-wapniowe, kompleksowe glinowe-bentonitowe);

- węglowodorowe (zwierające woski naftowe);

- z zagęszczaczami nieorganicznymi (bentonitowe, krzemionkowe, zawierające azotek boru, dwusiarczek molibdenu)

- $\quad$ z zagęszczaczami organicznymi (poliamidowe, polimoczniowe, zawierające polietylen, PTFE, grafit) (Mortier et al., 2010). Smary krzemionkowe są zaliczane do smarów wielofunkcyjnych i są znacznie lepsze pod względem odporności termicznej, na utlenianie oraz oddziaływania chemicznego niż odpowiednie smary mydlane. Mogą być stosowane do wysokich temperatur $160-180^{\circ} \mathrm{C}$, a w przypadku zastosowania olejów syntetycznych nawet do $200^{\circ} \mathrm{C}$. Do zalet smarów krzemionkowych zaliczyć można: bardzo dużą odporność na działanie wysokiej temperatury, dużą odporność na utlenianie, dużą odporność na działanie wody, pary wodnej, kwasów i alkaliów (Podniało, 2002). Smary te ze względu na bardzo dużą odporność na wysoką temperaturę nie posiadają punktu kroplenia - przy ogrzewaniu spaleniu ulega olej bazowy, podczas gdy zagęszczacz nie topi się (Czarny, 2004).

Brak jest informacji o ilościach produkowanych smarów krzemionkowych. Z raportu (Graese Production, 2008-2011) można wnioskować, że są to ilości bardzo niewielkie - około $2 \%$ to cała grupa smarów innych, z zagęszczaczami niemydlanymi. Przykładowe smary krzemionkowe zestawiono w tabeli 1.

Porównując właściwości smaru krzemionkowego ze smarem na bazie stearynianu wapnia (Bajer et al., 2011) stwierdzono, że charakteryzuje się on znacznie lepszymi właściwościami smarnymi - obciążeniem zespawania na poziomie $3500 \mathrm{~N}$ w porównaniu do około 1300 N. Smar krzemionkowy w porównaniu z litowym wykazuje też znacznie lepsze właściwości przeciwzużyciowe: czterokrotnie wyższy graniczny nacisk za$\operatorname{tarcia}\left(1300 \mathrm{~N} / \mathrm{mm}^{2}\right.$ a $\left.300 \mathrm{~N} / \mathrm{mm}^{2}\right)$, dwukrotnie wyższe obciążenie zacierające (1900 N a $900 \mathrm{~N})$, dwukrotnie wyższe graniczne obciążenie zatarcia (6800 N a $3500 \mathrm{~N}$ ) oraz półtora razy wyższe graniczne obciążenie zużycia $\left(600 \mathrm{~N} / \mathrm{mm}^{2}\right.$ a $\left.400 \mathrm{~N} / \mathrm{mm}^{2}\right)$.

$\mathrm{W}$ innej pracy badawczej realizowanej w ITEE analizowano stabilność termooksydacyjną smarów z zagęszczaczem nieorganicznym - krzemionką, wytworzonych na bazie olejów silikonowych (metylosilikonowego i fluorosilikonowym) modyfikowanych dodatkami: polimerowym, nanostrukturami węglowymi zawierającymi fullereny oraz graftem. Zaobserwowano, że spośród przebadanych próbek smarów najlepszą odpornością na utlenianie oznaczoną metodą Petrooxy charakteryzował się smar na bazie oleju fluorosilikonowego zawierający $1 \%(\mathrm{~m} / \mathrm{m})$ grafitu. Zaobserwowano, że spośród przebadanych próbek smarów, najlepszą odpornością na utlenianie w metodzie DSC (skaningowej kalorymetrii różnicowej), charakteryzował się smar na bazie oleju fluorosilikonowego zawierający 0,5\% ( $\mathrm{m} / \mathrm{m})$ nanostruktur węglowych (Drabik i Trzos, 2013).

Badając smary krzemionkowe wytworzone na różnych olejach bazowych: oleju parafinowym o czystości farmaceutycznej,

Tabela 1. Przykładowe smary krzemionkowe

Table 1. Examples of silica lubricants

\begin{tabular}{|c|c|c|c|c|}
\hline \multirow[t]{2}{*}{ Nazwa } & \multirow[t]{2}{*}{ Producent } & \multirow[t]{2}{*}{ Olej bazowy } & $\begin{array}{l}\text { Zakres pracy } \\
\text { od/do }\end{array}$ & \multirow[t]{2}{*}{ Zastosowanie smaru } \\
\hline & & & {$\left[{ }^{\circ} \mathbf{C}\right]$} & \\
\hline Vecosil FD 72 & Veco & - & $-25 / 100$ & $\begin{array}{l}\text { do łożysk w branży spożywczej, farmaceutycznej, kosmetycznej, dopusz- } \\
\text { czony do incydentalnego kontaktu z żywnością }\end{array}$ \\
\hline Dow Corning 4 & Molycote & silikonowy & $-55 / 200$ & uszczelniający, dopuszczony do incydentalnego kontaktu z żywnością \\
\hline NyoGel 760G & ARMYTEK & PAO & $-40 / 135$ & do latarek oraz styków urządzeń elektrycznych \\
\hline Loctite 8104 & Henkel & silikonowy & $-50 / 200$ & $\begin{array}{l}\text { w przemyśle spożywczym do zaworów i dławic, może być także uży- } \\
\text { wany do wolnoobrotowych łożysk }\end{array}$ \\
\hline $\begin{array}{l}\text { High Vacuum } \\
\text { Grease }\end{array}$ & Dow Corning & silikonowy & $-40 / 200$ & $\begin{array}{l}\text { środek smarowy i uszczelniający o dobrej odporności na większość } \\
\text { związków chemicznych do zaworów, uszczelek i części pracujących } \\
\text { w warunkach próżni, do łożysk obrotowych i ceramicznych }\end{array}$ \\
\hline
\end{tabular}


PAO i oleju rzepakowym, przy tej samej ilości zagęszczacza na poziomie 10\% (Kozdrach, 2012) stwierdzono, że lepkość fazy dyspergującej w smarach oraz jej charakter chemiczny wpływa na właściwości tribologiczne. Przeprowadzone badania wykazały, że smar na bazie oleju roślinnego charakteryzuje się dużą skutecznością ochrony węzła tarcia przed zużyciem i zacieraniem. Smar na bazie oleju mineralnego, zapewniając skuteczną ochronę przeciwzużyciową nie zapewnia ochrony przeciwzatarciowej w warunkach zacierania. Smar na bazie polialfaolefin wykazuje bardzo słabe właściwości przeciwzatarciowe i znacznie słabsze właściwości przeciwzużyciowe niż dwa inne badane smary.

Dla smaru krzemionkowego w klasie konsystencji NLGI 2, o zawartości 8\% zagęszczacza, wytworzonego na bazie parafiny farmaceutycznej (Kozdrach, 2016), przedstawiono zmiany właściwości tribologicznych smaru po poddaniu go ścinaniu w naczyniu penetracyjnym. Próbki smarów poddawano wielokrotnemu ugniataniu: 60, 250, 500, 1000, 3000, 5000 i 10000 razy. Zaobserwowano, że ze wzrostem krotności ugniatania, rosła penetracja smarów (od 270 do $401 \mathrm{~mm} / 10$ ), a także temperatura kroplenia (od 195 do $216^{\circ} \mathrm{C}$ ), Następnie po tych wymuszeniach mechanicznych, próbki poddano badaniom właściwości smarnych i przeciwzużyciowych na aparacie czterokulowym. Oceniono obciążenie zespawania, graniczne obciążenie zużycia, graniczne obciążenie zatarcia, obciążenie niezacierające i graniczny nacisk zatarcia. Zaobserwowano, że ze wzrostem wymuszenia mechanicznego do 500 podwójnych suwów tłoka podczas ugniatania smaru, rosną wszystkie wyżej wymienione parametry $\mathrm{w}$ badaniach tribologicznych, a następnie podczas kolejnych wymuszeń parametry te już maleją. Wymuszenia (od 60 do 500-krotnego ugniatania smaru) skutkują wytworzeniem filmu ochronnego na powierzchni, co wpływa na wzrost odporności węzła na zacieranie - następuje ono przy większym obciążeniu węzła tarcia. Stwierdzono, że proces ugniatania smaru skutecznie modyfikuje właściwości przeciwzatarciowe i przeciwzużyciowe smarów krzemionkowych.

Analizowano wpływ krzemionek na właściwości prostych smarów litowych wytworzonych na bazie oleju metylosilikonowego i syntetycznego oleju estrowego (Pawelec i Drabik, 2008). Zastosowano krzemionki płomieniowe o zróżnicowanej powierzchni właściwej (100 i $200 \mathrm{~m}^{2} / \mathrm{g}$ ), charakteryzujące się nietoksycznością i dopuszczeniem do zastosowania w przemyśle spożywczym. Do próbek smarów litowych, zawierających 10-18\% zagęszczacza w postaci 12-hydroksystearynianu litu, wprowadzano (jako modyfikatory właściwości) dwa rodzaje krzemionek, w ilościach 3-10\%. Stwierdzono decydujący wpływ koncentracji zagęszczacza i zastosowanych krzemionek na właściwości reologiczne smarów (określane wartością penetracji) oraz wzrost odporności termicznej (określone temperaturą kroplenia). Nie uzyskano smarów o temperaturze kroplenia powyżej $200^{\circ} \mathrm{C}$.

Badano odporność smarów litowych z krzemionką na powierzchniowe zużycie zmęczeniowe (Molenda i Kozdrach, 2012). Smary te wytworzone na oleju parafinowym, rzepakowym i PAO, w klasie konsystencji NLGI 2, modyfikowane były $10 \%$ dodatkiem polimerowo-krzemionkowym (PTFE z krzemionką amorficzną o rozmiarach $7 \mathrm{~nm}$ w udziale masowym 3:2). Stwierdzono, że modyfikacja wyżej wymienionym dodatkiem smarów na bazie oleju mineralnego i roślinnego zwiększa poziom odporności smarów powierzchniowe na zużycie zmęczeniowe, a w przypadku smarów na bazie PAO - obniża tę właściwość. Przeprowadzone badania potwierdziły, że lepkość fazy dyspergującej w smarach oraz jej charakter chemiczny wpływa na parametry powierzchniowego zużycia zmęczeniowego.

Porównano właściwości tribologiczych smarów na bazie rafinowanego oleju lnianego, o różnych zagęszczaczach, w klasie konsystencji NLGI 2 (Kozdrach, 2018). Przeprowadzone badania wykazały zróżnicowany wpływ fazy zdyspergowanej na właściwości przeciwzatarciowe i przeciwużyciowe smarów. Smary krzemionkowe charakteryzowały się bardzo dobrymi właściwościami przeciwzatarciowymi w warunkach stopniowo narastającego obciążenia węzła tarcia, natomiast smary litowe nie zapewniały tej ochrony dostatecznie. Zastosowanie krzemionki amorficznej jako zagęszczacza smaru powoduje utworzenie ochronnego filmu na powierzchni, co prowadzi do zwiększenia odporności węzła na zacieranie i chroni przed zużyciem.

Znane są patenty dotyczące smarów krzemionkowych:

- PL 202417 - smar plastyczny używany zwłaszcza do maszyn i urządzeń przemysłu spożywczego, na bazie oleju silikonowego, zawierający jako zagęszczacz 5-25\% krzemionki płomieniowej;

- PL 212922 - wysokotemperaturowy smar plastyczny o podwyższonej adhezji do podłoża stalowego przeznaczony do maszyn przemysłu spożywczego, na bazie syntetycznego oleju estrowego, zagęszczacza w postaci $2-5 \%$ hydrofilowej krzemionki płomieniowej oraz dodatku reologicznego w postaci 9-13\% hydrofobowej krzemionki płomieniowej; - PL 224217 - wysokotemperaturowy syntetyczny smar plastyczny do stalowych węzłów tarcia, na bazie oleju syntetycznego (korzystnie oleju silikonowego o lepkości kinematycznej $100-500 \mathrm{~mm}^{2} / \mathrm{s}$ w temperaturze $25^{\circ} \mathrm{C}$ ), zawierający $1-8 \%$ modyfikowanej krzemionki oraz $1-12 \%$ substancji mineralnej o budowie warstwowej, korzystnie krzemianu metali dwu- i trójwartościowych;

- PL 229935 - wysokospecjalistyczny smar plastyczny używany zwłaszcza do maszyn i urządzeń przemysłu spożywczego, na bazie oleju fluorosilikonowego (o lepkości 
kinematycznej w temperaturze $40^{\circ} \mathrm{C}, 1000 \mathrm{~mm}^{2} / \mathrm{s}$ ) i co najmniej $2 \%$ zagęszczacza nieorganicznego w postaci hydrofilowej krzemionki płomieniowej o powierzchni właściwej $300 \mathrm{~m}^{2} / \mathrm{g}$ oraz zawierający modyfikator właściwości - 10\% hydrofobowej krzemionki o powierzchni właściwej $110 \mathrm{~m}^{2} / \mathrm{g}$;

- PL 212382 - syntetyczny smar plastyczny zwłaszcza do maszyn i urządzeń pracujących w niskich temperaturach, na bazie oleju PAO, modyfikowanej krzemionki hydrofilowej o powierzchni właściwej $200 \mathrm{~m}^{2} / \mathrm{g}$ w ilości 6,58\% oraz talku w ilości $11,42 \%$.

\section{Część doświadczalna}

Próbki smarów krzemionkowych wytworzono w klasie konsystencji NLGI 2, na bazie olejów bazowych o różnym charakterze chemicznym i hydrofobowych krzemionek, w ilościach $15-17 \%(\mathrm{~m} / \mathrm{m})$. Aby ocenić wpływ oleju bazowego i zagęszczacza otrzymanych próbek smarów nie wzbogacano o dodatki funkcyjne.

Zastosowano oleje bazowe (właściwości w tabeli 2):

- A: SAE 30/95 - olej o charakterze parafinowym grupy I według API, produkcji GRUPY LOTOS S.A.;

- B: T 110 - olej o charakterze naftenowym grupy V według API, produkcji NYNAS AB;

- CD: mieszaninę w proporcji 1:1 olejów polialfaolefinowych grupy IV według API;

- C: Synfluid PAO 6, produkcji Chevron Phillips Chemical,

- D: Luvodur PAO 400, produkcji Lehmann \& Voss \& Co.;

- E: Priolube 3999 - olej estrowy grupy V według API, produkcji CRODA Lubricants;

- F: Olej rzepakowy - olej roślinny pochodzenia naturalnego, produkcji ZT Kruszwica SA.

Do wytworzenia zagęszczacza próbek smarów wykorzystano dwa rodzaje krzemionki hydrofobowej, produkcji Evonic
Industries. Smary na bazie olejów A-D zagęszczono krzemionką Aerosil R 974 (o powierzchni właściwej $100 \pm 20 \mathrm{~m}^{2} / \mathrm{g}$ ), a smary na bazie olejów E i F - krzemionką Aerosil R 202 (o powierzchni właściwej $170 \pm 20 \mathrm{~m}^{2} / \mathrm{g}$ ).

Smary krzemionkowe wytworzono w reaktorze o pojemności 1,5 kg, ogrzewanym elektrycznie, wyposażonym w mieszadło z bocznymi skrobakami, poprzez zdyspergowanie hydrofobowej krzemionki w oleju bazowym, podgrzanym do temperatury $100-120^{\circ} \mathrm{C}$. Po ochłodzeniu do temperatury około $70^{\circ} \mathrm{C}$ smar poddano homogenizacji w tarczowym młynie koloidalnym typu Fryma, przy szczelinie 0,2 mm. Wygląd smarów przedstawiono na rysunku 1 , a ich parametry w tabeli 3 .

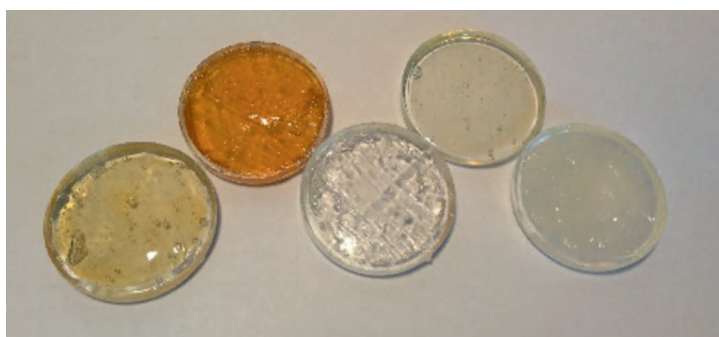

Rys. 1. Smary krzemionkowe - od lewej - ASA, SB, SCD, SE, SF Fig. 1. Silica greases - from left to right - ASA, SB, SCD, SE, SF

Wszystkie uzyskane próbki smarów krzemionkowych charakteryzują się bardzo wysoką temperaturą kroplenia. Nie kroplą do temperatury $300^{\circ} \mathrm{C}$, co pozwala na zastosowanie ich w wysokich temperaturach. Do oznaczenia górnej granicy pracy smarów, zgodnie z wymaganiami normy PN-ISO12924 (Zajezierska, 2012) należy wykonać badanie trwałości eksploatacyjnej smaru na stanowisku FAG FE 9 - według metodyki DIN 51821. Dla smarów o maksymalnej temperaturze stosowania powyżej $120^{\circ} \mathrm{C}$ trwałość eksploatacyjna łożyska $\mathrm{F}_{50}$ powinna wynosić powyżej 100 godzin.

Uzyskane próbki smarów na bazie olejów PAO, syntetycznym estrowym i rzepakowym (SCD, SE, SF) charakteryzują się wartością penetracji w temperaturze $-30^{\circ} \mathrm{C}$ powyżej 120 mm/10. Zgodnie z wymaganiami normy PN-ISO12924

Tabela 2. Oznaczone właściwości fizykochemiczne olejów bazowych

Table 2. Determined physicochemical properties of base oils

\begin{tabular}{|c|c|c|c|c|c|c|c|c|}
\hline Wlaściwości & Jednostka & $\mathbf{A}$ & B & $\mathbf{C}$ & D & $\mathbf{E}$ & $\mathbf{F}$ & Metoda badań \\
\hline Lepkość kinematyczna & \multirow{3}{*}[\mathrm{mm}^{2}/\mathrm{s}]{} & & & & & & & \\
\hline$-\mathrm{w} 40^{\circ} \mathrm{C}$ & & 86,59 & 107,20 & 29,94 & 402,20 & 125,40 & 33,56 & \multirow{2}{*}{ PN-EN ISO 3104} \\
\hline$-\mathrm{w} 100^{\circ} \mathrm{C}$ & & 10,24 & 8,927 & 5,768 & 40,58 & 14,40 & 8,257 & \\
\hline Wskaźnik lepkości & - & 99 & 28 & 138 & 260 & 155 & 207 & PN-ISO 2909 \\
\hline Barwa & - & 1,5 & 2,0 & 0 & 0 & 0,5 & 0,5 & PN-ISO 2049 \\
\hline Temperatura płynięcia & {$\left[{ }^{\circ} \mathrm{C}\right]$} & -12 & -30 & -66 & -42 & -27 & -21 & PN-ISO 3016 \\
\hline Liczba kwasowa & {$[\mathrm{mg} \mathrm{KOH} / \mathrm{g}]$} & 0,015 & 0,010 & 0,045 & 0,145 & 1,569 & 0,079 & PN-ISO 6618 \\
\hline Temperatura zapłonu & {$\left[{ }^{\circ} \mathrm{C}\right]$} & 220 & 214 & 245 & 287 & 297 & 325 & PN-EN ISO 2592 \\
\hline
\end{tabular}


Tabela 3. Właściwości wytworzonych próbek smarów krzemionkowych

Table 3. Properties of manufactured silica grease samples

\begin{tabular}{|c|c|c|c|c|c|c|c|}
\hline Wlaściwości & Jednostka & SA & SB & SCD & SE & SF & Metody badań \\
\hline Penetracja w temperaturze $25^{\circ} \mathrm{C}$, po ugniataniu $60 \mathrm{x}$ & {$[\mathrm{mm} / 10]$} & 295 & 265 & 273 & 289 & 283 & PN-ISO 2137 \\
\hline Temperatura kroplenia & {$\left[{ }^{\circ} \mathrm{C}\right]$} & $>300$ & $>300$ & $>300$ & $>300$ & $>300$ & PN-ISO 2176 \\
\hline $\begin{array}{l}\text { Stabilność mechaniczna, zmiana penetracji smaru w } \\
25^{\circ} \mathrm{C} \text {, po wałkowaniu smaru w temperaturze } 60^{\circ} \mathrm{C} \\
\text { przez } 4 \text { godziny }\end{array}$ & [\%] & 0,9 & 1,4 & 1,5 & 7,4 & 2,9 & PN-C-04144 \\
\hline $\begin{array}{l}\text { Wydzielanie oleju ze smaru w temperaturze } 100^{\circ} \mathrm{C} \\
\text { przez } 24 \text { godziny }\end{array}$ & {$[\%(m / m)]$} & 0,9 & 0,5 & 0,36 & 1,31 & 1,1 & PN-V-04047 \\
\hline $\begin{array}{l}\text { Wydzielanie oleju ze smaru w temperaturze } 40^{\circ} \mathrm{C} \\
\text { przez } 18 \text { godzin, pod obciążeniem }\end{array}$ & {$[\%(m / m)]$} & 0,2 & 0,40 & 0,45 & 1,30 & 0,63 & PN-C-96016 \\
\hline Penetracja w temperaturze $-20^{\circ} \mathrm{C}$ & {$[\mathrm{mm} / 10]$} & 142 & 133 & - & - & - & PN-ISO 3737 \\
\hline Penetracja w temperaturze $-30^{\circ} \mathrm{C}$ & {$[\mathrm{mm} / 10]$} & 98 & 106 & 185 & 174 & 156 & PN-ISO 3737 \\
\hline $\begin{array}{l}\text { Odporność na wymywanie wodą metodą statyczną, } \\
\text { w temperaturze } 90^{\circ} \mathrm{C}\end{array}$ & - & $0-90$ & $0-90$ & $0-90$ & $1-90$ & $1-90$ & PN-C-96013 \\
\hline $\begin{array}{l}\text { Odporność na wymywanie wodą metodą dynamicz- } \\
\text { ną, w temperaturze } 79^{\circ} \mathrm{C}\end{array}$ & {$[\%(m / m)]$} & 0,25 & 0,25 & 1,5 & 1,0 & 0,52 & PN-ISO 1009 \\
\hline
\end{tabular}

można określić dolną granicę stosowania tych smarów na poziomie $-30^{\circ} \mathrm{C}$. Uzyskane próbki smarów na bazie olejów mineralnych (SA i SB) charakteryzują się wartością penetracji w temperaturze $-20^{\circ} \mathrm{C}$ powyżej $120 \mathrm{~mm} / 10$. Zgodnie z wymaganiami normy PN-ISO12924 można określić dolną granicę stosowania tych smarów na poziomie $-20^{\circ} \mathrm{C}$.

Wytworzone próbki smarów na bazie olejów mineralnych i PAO (SA, SB, SCD) charakteryzują się doskonałą stabilnością mechaniczną - na poziomie poniżej $2 \%$, a smary na bazach biodegradowalnych - znacznie poniżej 10\%. Dla porównania, smary litowe obecne na rynku, charakteryzują się stabilnością mechaniczną na poziomie kilkunastu procent, natomiast wymagania dla samochodowego smaru ŁT-4S, zgodnie z BN-73/0536-15, wynoszą odpowiednio: dla smaru NLGI 3 - poniżej $20 \%$, a dla klasy 2 według NLGI - poniżej $25 \%$.

Wysokotemperaturowe smary bentonitowe oraz smary na innym zagęszczaczu nieorganicznym charakteryzują się bardzo słabą stabilnością mechaniczną - przekraczającą nawet 100\% (Stachurska, 2017; Bentor 2).

Wszystkie uzyskane próbki smarów krzemionkowych charakteryzują się bardzo dobrą stabilnością strukturalną, potwierdzoną w badaniach skłonności smarów do wydzielania oleju. Zarówno w badaniu wydzielania oleju w wysokiej temperaturze, jak i pod obciążeniem uzyskane wyniki nie przekraczają $1,5 \%(\mathrm{~m} / \mathrm{m})$.

Wytworzone próbki smarów na bazie olejów mineralnych i PAO (SA, SB, SCD) charakteryzują się bardzo dobrą odpornością na wymywanie gorącą wodą w metodzie statycznej - nie zmieniają swojego wyglądu. Dla próbek smarów na bazach biodegradowalnych odporność ta jest nieco słabsza - nastąpiło niewielkie zemulgowanie na powierzchni smaru.
Wszystkie uzyskane próbki smarów krzemionkowych charakteryzują się bardzo dobrą odpornością na działanie wody w metodzie dynamicznej - podczas natrysku wody o temperaturze $79^{\circ} \mathrm{C}$ na obracające się łożysko. Uzyskane wyniki nie przekraczają $1,5 \%(\mathrm{~m} / \mathrm{m})$.

\section{Podsumowanie}

Zalety smarów krzemionkowych, takich jak: bardzo wysoka temperatura kroplenia, doskonała stabilność mechaniczna, dobra stabilność strukturalna oraz bardzo dobra odporność na wymywanie wodą pozwalają na zastosowanie tych smarów w trudnych warunkach eksploatacyjnych.

Artykuł powstał na podstawie pracy statutowej pt.: Opracowanie założeń dla technologii smaru hybrydowego - praca INiG - PIB na zlecenie MNiSW; nr zlecenia: 0019/TO/2019, nr archiwalny: DK-4100-411/2019.

\section{Literatura}

Bajer J., Drabik J., Kozdrach R., 2011. Wpływ rodzaju zagęszczacza na charakterystyki tribologiczne smarów plastycznych. Tribologia, 1: 73-83.

Bentor 2. Oferta Grupy Orlen. www.orlenoil.pl/PL/NaszaOferta/ Produkty/Strony/BENTOR_2.aspx (dostęp: 13.08.2019).

Czarny R., 2004. Smary plastyczne. Wydawnictwa NaukowoTechniczne, Warszawa.

Drabik J., Trzos M., 2013. Improvement of the resistance to oxidation of ecological greases by the additives. J. Therm. Anal. Calorim., 113: 357-363.

Grease Production Survey Report 2008-2011, NLGI.

Kozdrach R., 2012. Wpływ rodzaju fazy dyspergującej na właściwości tribologiczne smarów plastycznych. Tribologia, 6: 85-97. 
Kozdrach R., 2016. Wpływ wymuszeń mechanicznych na zmianę właściwości tribologicznych smarów plastycznych wytworzonych na bazie mineralnej. Nafta-Gaz, 1: 50-57. DOI: 10.18668/ NG.2016.01.07.

Kozdrach R., 2018. Wpływ rodzaju fazy zdyspergowanej na właściwości tribologiczne smarów plastycznych wytworzonych na oleju lnianym. Nafta-Gaz, 6: 471-478. DOI: 10.18668/NG.2018.06.08.

Krawiec S., 2011. Kompozycje smarów plastycznych i stałych w procesie tarcia stalowych węzłów maszyn. Oficyna Wydawnicza Politechniki Wrocławskiej, Wrocław.

Molenda J., Kozdrach R., 2012. Testowanie właściwości eksploatacyjnych ekologicznych smarów plastycznych modyfikowanych dodatkiem polimerowo-krzemionkowym. Tribologia, 6: 99-111.

Mortier R.M., Fox M.F., Orszulik S., 2010. Chemistry and Technology of Lubricants, Wyd. Springer, 411-432.

Pawelec E., Drabik J., 2008. Wpływ niekonwencjonalnych modyfikatorów na stabilność strukturalną i odporność termiczną wysokotemperaturowego smaru plastycznego. Część 1. Tribologia, 3: $235-246$.

Podniało A., 2002. Paliwa, oleje i smary w eksploatacji. Wydawnictwa Naukowo-Techniczne, Warszawa.

Stachurska P., 2017. Badanie wpływu charakteru olejów bazowych na właściwości smarów bentonitowych. Nafta-Gaz, 9: 707-714. DOI: 10.18668/NG.2017.09.11.

TOTAL - Poradnik. Smary plastyczne. Rozdział XIX. www.total. com.pl/pro/B2B-produkty-dla-przemyslu/li-materialy-informacyjne/li-poradnik.html (dostęp: 13.08.2019).

Zajezierska A., 2012. Smary plastyczne - europejskie normy klasyfikacyjne i wymagania jakościowe. Nafta-Gaz, 10: 714-720.

\section{Akty normatywne}

BN-73/0536-15 Smary smamochodowe $Ł T-4 S$.

DIN 51821-2:2016 Prüfung von Schmierstoffen - Prüfung von Schmierfetten auf dem FAG-Wälzlagerfett-Prüfgerät FE9 - Teil 2: Prüfverfahren.

PN-C-04144:1962 Przetwory naftowe - Oznaczanie stabilności mechanicznej smarów statych.

PN-C-96013:2014 Badanie smarów - Badanie zachowania się smarów plastycznych $w$ obecności wody - Badanie $w$ warunkach statycznych.

PN-C-96016:2014 Badanie środków smarowych - Oznaczanie wydzielania oleju ze smaru plastycznego w warunkach statycznych.

PN-EN ISO 2592:2017 Przetwory naftowe i produkty podobne Oznaczanie temperatury zapłonu i palenia-Metoda otwartego tygla Clevelanda.

PN-EN ISO 3104:2004 Przetwory naftowe - Ciecze przezroczyste i nieprzezroczyste - Oznaczanie lepkości kinematycznej i obliczanie lepkości dynamicznej.
PN-ISO 11009:2011 Przetwory naftowe i środki smarowe - Badanie odporności smarów plastycznych na wymywanie woda.

PN-ISO 13737:2011 Przetwory naftowe i środki smarowe-Pomiar penetracji smarów plastycznych $w$ niskich temperaturach penetrometrem ze stożkiem.

PN-ISO 2049:2010 Przetwory naftowe - Oznaczanie barwy (skala ASTM).

PN-ISO 2137:2011 Przetwory naftowe i środki smarowe - Oznaczanie stożkiem penetracji smarów plastycznych i petrolatum.

PN-ISO 2176:2011 Przetwory naftowe - Smary plastyczne Oznaczanie temperatury kroplenia.

PN-ISO 2909:2009 + Ap1:2010 Przetwory naftowe - Obliczanie wskaźnika lepkości na podstawie lepkości kinematycznej.

PN-ISO 3016:2005 Przetwory naftowe - Oznaczanie temperatury ptynięcia.

PN-ISO 6618:2011 Przetwory naftowe i środki smarowe - Oznaczanie liczby kwasowej i zasadowej. Metoda miareczkowania wobec wskaźników barwnych.

PN-ISO12924:2012 Środki smarowe, oleje przemysłowe i produkty podobne (Klasa L) Grupa X (Smary).

PN-V-04047:2002 Przetwory naftowe - Badanie wydzielania oleju ze smaru $w$ wysokich temperaturach.

\section{Patenty}

Patent 202417 Smar plastyczny zwłaszcza do maszyn i urządzeń przemystu spożywczego (data publikacji: 11.07.2005).

Patent 212382 Syntetyczny smar plastyczny zwłaszcza do maszyn i urządzeń pracujacych $w$ niskich temperaturach (data publikacji 07.07.2008).

Patent 212922 Wysokotemperaturowy smar plastyczny o podwyższonej adhezji do podtoża stalowego przeznaczony do maszyn przemystu spożywczego (data publikacji: 21.06.2010).

Patent 224217 Wysokotemperaturowy syntetyczny smar plastyczny do stalowych węzłów tarcia (data publikacji: 09.06.2014).

Patent 229935 Wysokospecjalistyczny smar plastyczny zwłaszcza do maszyn i urządzeń przemystu spożywczego (data publikacji: 06.06.2016).

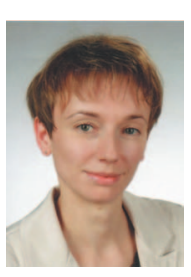

Mgr inż. Agnieszka SKIBIŃSKA

Asystent w Zakładzie Olejów, Środków Smarowych i Asfaltów

Instytut Nafty i Gazu - Państwowy Instytut Badawczy ul. Lubicz $25 \mathrm{~A}$

31-503 Kraków

E-mail: agnieszka.skibinska@inig.pl 